\title{
THE CONSUMPTION OF ORGANIC FOODS BY THE STUDENT POPULATION IN THE REPUBLIC OF SERBIA
}

Vladanka Palić1, Dušan Cogoljević2 ${ }^{2}$ Zorana Nikitović ${ }^{3}$ Slađana Vujičićc

*Corresponding authorE-mail: sladjana.vujicic@vspep.edu.rs

\begin{abstract}
A R T I C LE IN F O
A B S T R A C T

Original Article

Received: 24 May 2019

The beginning of the 21 st century has noted a change in the attitude of modern man towards health and the pursuit Accepted: 17 September 2019 of a healthy lifestyle. Thus, particular emphasis is placed on the importance of a healthy diet and a healthy lifestyle. doi:10.5937/ekoPolj1903771P UDC 631.147:057.87(497.11) The importance of nourishing nutrition and health-related issues has been recognized and raised on the state level.

Keywords:

organic food, healthy life, Serbia Thus, numerous national campaigns promote healthy nutrition aimed at improving the overall health of the nation. Health in general, as well as healthy eating habits, are today very important political and economic issues in developed countries. On the contrary, in underdeveloped JEL : $L 66$ countries, food shortage is not uncommon. The Republic of Serbia has high-quality and healthy food, but consumer awareness regarding this issue is insufficiently developed. The aim of this paper is to determine the level of the consumption of organic foods by the student population and the awareness of good nutrition and a healthy lifestyle. The research was conducted in the Danube Region within the Republic of Serbia.
\end{abstract}

(C) 2019 EA. All rights reserved.

\section{Introduction}

In the EU food market, different food labeling schemes co-exist with the aim of informing customers and providing trust on different quality characteristics of food

1 Vladanka Palić,MA, Faculty of Business Economics and Entrepreneurship, Mitropolita Petra 8, Belgrade, Serbia 064 2391289,e-mail:djurazo001@gmail.com, ORCID ID https:// orcid.org/0000-0002-4096-0677

2 Dušan Cogoljević,Associate Professor,Faculty ofBusiness Economics and Entrepreneurship, Mitropolita Petra 8, Belgrade, Serbia, 065 2960000, e-mail::dusan.cogoljevic@vspep.edu. rs, ORCID ID https://orcid.org/0000-0002-3548-0329

3 Zorana Nikitović, Associate Professor,Faculty of Business Economics and Entrepreneurship, Mitropolita Petra 8, Belgrade, Serbia, 063 1028842, e-mail:zorana.nikitovic@vspep.edu.rs, ORCID ID https://orcid.org/0000-0003-1443-7345

4 Sladjana Vujičić, Associate Professor, Faculty of Business Economics and Entrepreneurship, Mitropolita Petra 8,Belgrade,Serbia, 069 0278527, e-mail:sladjana.vujicic@vspep.edu.rs, ORCID ID https://orcid.org/0000-0002-8532-2644 
products (Gracia, de-Magistris, 2015). According to European research papers dealing with consumer attitudes towards food and the importance of nutrition for health, health is one of the four most important reasons for making specific food choices. It should be noted that there are some differences in food consumption between individual countries in terms of consumption of fruits and vegetables or the avoidance of fatty foods, as well as attitudes towards natural foods.

The five most important factors in fifteen European countries which influence food choices are the quality or freshness of food, price, taste, health and preferences or wishes of the household members. The results of a US-related research have shown that the most important factor is the taste of food, followed by the price or costs associated with food consumption, nutrition, convenience and issues related to obesity.

Over the last decade, the organic food sector has been one of the fastest growing segments in the global food market (Sahota, 2015). The extensive amount of the research that is carried out into the relationship between organic food and health defines ,health $\square$ as one of the primary reasons why consumers buy and consume organic food (Zanoli \& Naspetti, 2002).

Many of the final consumer surveys analyzed the reasons for buying healthy food. In general terms, consumer health and food safety are the most important reasons for purchasing healthy foods. For example, the basic reasons for buying organic products are usefulness, a lack of chemicals, ecology and a good taste; while the appearance of food, ease of preparation and convenience to maintain a normal weight is of a minor importance to the consumers of these products, relative to the general population.

The purchase of organic products reflects the lifestyle of consumers, and it is linked to their system of values, attitudes, and especially with their ecological awareness. For example, organic food purchasers belong to the group of dedicated 'green' consumers. Such customers consider themselves responsible for their health and believe that it is influenced by the choice and consumption of food. They also know more about nutrition than other consumers and are willing to undergo some extra costs, the appearance and ease of food preparation.

\section{Consumption of organic food in the Republic of Serbia}

Organic agriculture protects the natural environment and is a prospective activity in the economy, as it contributes to the optimal use of resources, the development of rural areas and villages, sustainable exports, economic growth, and the increase in living standards (Lazić, 2010). The market and the demand for organic products are constantly increasing, and the areas under this production are increasing from day to day (Golijan, Popović, 2016).

Consumers in the European Union spent 23.9 billion euros on organic food (Kranjac,et al, 2017). Germany is the biggest organic market in Europe with a share of $30 \%$ of retail sales. It is followed by France (18\%), the United Kingdom (9\%) and Italy (8\%) 
(Heinze, 2016). Total areas under the organic production in the Republic of Serbia stretch on area of 15,298.02 ha (Ministry of Agriculture and Environmental Protection, 2016). The food increasing production, competitiveness and accelerated development and introduction of agrarian policy instruments that allow dynamic restructuring of the agricultural sector (Zakić, Bugarčić,Milovanović,2017).

Organic agriculture is the most acceptable form of agriculture in regards to ecological criteria, and it has a far wider meaning than the usual explanation of "agriculture without the use of chemicals" (Vlahović et al., 2011). Organic food is hygienically correct and safe with an increased biological and nutritional value, a high content of vitamins and minerals, as well as promoting and improving biodiversity, biological cycles and activities (Ristić, Bošković, Knežević, 2018). We have a lot of difference between organic and conventional food production, table 1.

Table 1: The difference between organic and conventional food production

\begin{tabular}{|c|c|}
\hline Organic production & Conventional production \\
\hline Using organic fertilizer & Using synthetic fertilizer \\
\hline Reduced processing & Intensive processing \\
\hline Mechanical weed destroying & Use of herbicides \\
\hline Regulating fertility, pests, illnesses and weeds & Use of pesticides and other chemicals \\
\hline Pollination with bees and other insects & Use of suspensions \\
\hline Water distribution with capillary action & Irrigation \\
\hline Preserving flora and fauna diversity & Use of synthetic soil improvers ground \\
\hline Composting, returning herbal remnants to the ground & Pesticide pollution \\
\hline Environmental protection & insecticides \\
\hline
\end{tabular}

Source: Ristic, at al., 2018

Research carried out in the Republic of Serbia during the previous period has shown that organic food producers need the most financial support from the state by subsidizing organic production and obtaining the necessary certificates. The problem is a long waiting period for financial backing, as well as high prices of raw materials (certified seeds) and organic fertilizers.

Djokić, Grubor, Milićević and Petrov (2018) point out that those mostly inclined towards organic foods are consumers who, according to their lifestyle, are 'adventurers.' These consumers are considered (Grubor, Djokić, Milićević, 2018) to be the most educated, to include the whole family in the process of preparing food, and to readily 
accept culinary innovations. In addition, the biggest obstacle to increasing the future consumption of organic foods in this segment is not the premium price of organic food, but the problems of its availability on the domestic market.

Most organic food producers see an improvement in the position of exporting produced organic foods and believe they can satisfy potential foreign buyers.

\section{Empirical research}

In order to examine the consumption of organic food by students in the Danube district within the Republic of Serbia, a survey was conducted in 2018 on a sample of 150 student respondents.

Students were questioned about their eating habits and the possibilities of production and consumption of organic food. All respondents are from the Danube Region, primarily the territory of the town of Smederevska Palanka and its surroundings.

\section{Research results}

Analysis and presentation of results:

The survey involved 150 respondents, of whom 87 were male (58\%) and 63 female (42\%), figure $1 .$.

Figure 1. Structure of respondents.

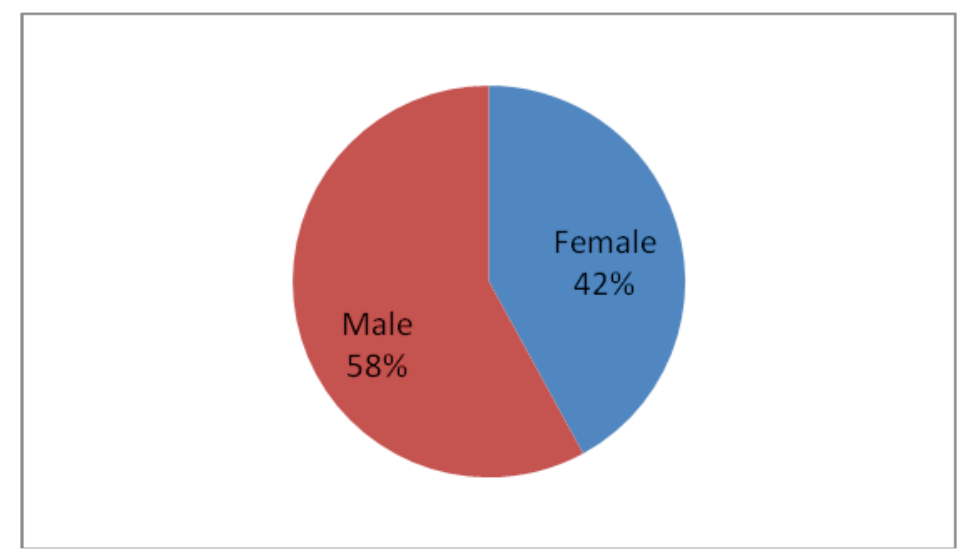

Source:Author's calculation

In terms of educational structure, a survey carried out through a questionnaire on a sample of 150 respondents showed that $91 \%$ of respondents have a secondary school degree, $7 \%$ of students are students with a Bachelor's degree and only $2 \%$ who are with Master's degree.

The food quality in Serbia is not equal to the quality in the European Union although the prices are European, and in some cases, such as meat and meat products, they are higher by 20 to 30 percent. 
Figure 2. Does the price of food affect your choice?

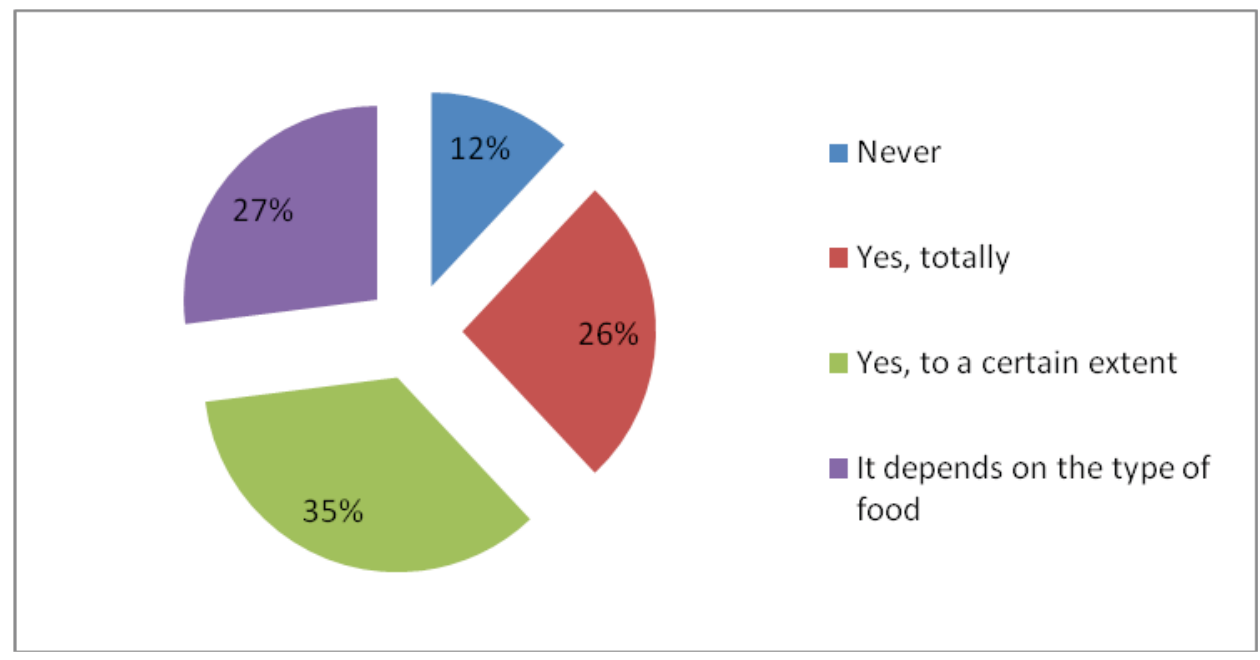

Source:Author's calculation

According to the results, price is a very important factor when choosing food. Namely, 52 students replied that the price affects their choice of food to some extent, 39 students said that the price totally affects the choice of food, 41 respondents answered that this depends on the type of food, while 18 students answered that food choice is never affected by the price, figure 2 .

According to these results, the following can be concluded: the price of food is a very important factor, which, considering the living standard of the population of Serbia, in this case student income, could be perceived as logical. More than half of the respondents considered the price to be a limiting factor when shopping for groceries.

The analysis further explores whether price has an impact and what kind, depending on the gender and age of the respondents.

The organic food production process is more complicated and therefore more expensive, which is reflected on its final price - organic products in our country can be up to $40 \%$ more expensive than those from the conventional agricultural production.

By using an example, we will show the difference between these two types of production. The production of organic bread in many ways differs from the production of the ordinary kind. The entire production process takes place in ecologically strictly controlled conditions. Organic wheat has no residue of heavy metals or chemicals which means that the wheat, barley, oats or rye used to make these products are not sprayed with pesticides and herbicides, but protected and fertilized by natural materials. Also, cereals are ground on stone. Therefore, the costs of organic bread production are higher so it is not possible to buy that sort of bread for 40-50 dinars, which is the price of white bread. In fact, a loaf of organic bread weighing 300 grams costs 109 dinars, while a loaf 
of bread with a sprinkling of flax, sunflower and pumpkin seeds of the same weight is 139 dinars.

As already noted, food quality in Serbia does not match up to EU quality but the prices are European, and in some cases, such as meat and meat products, higher by $20-40 \%$. Also, Serbian consumers, due to poverty and deprivation, are driven by the price when buying certain products, especially cured meat products, so they are not selective. Rather, they purchase according to what they can afford, even at the expense of their own health.

Research has shown that a number of students spend a large sum of money on food. As many as 98 students answered that they shelled out a lot of money for food, while 52 students replied that they did not set aside a lot of money on food.

When we compare the replies in regards to the gender and age of the respondents, we also get similar data regardless of the gender and age of the respondents, which can be seen in Figure 3.

Figure 3: Separating money for food, depending on the gender and age of the respondents

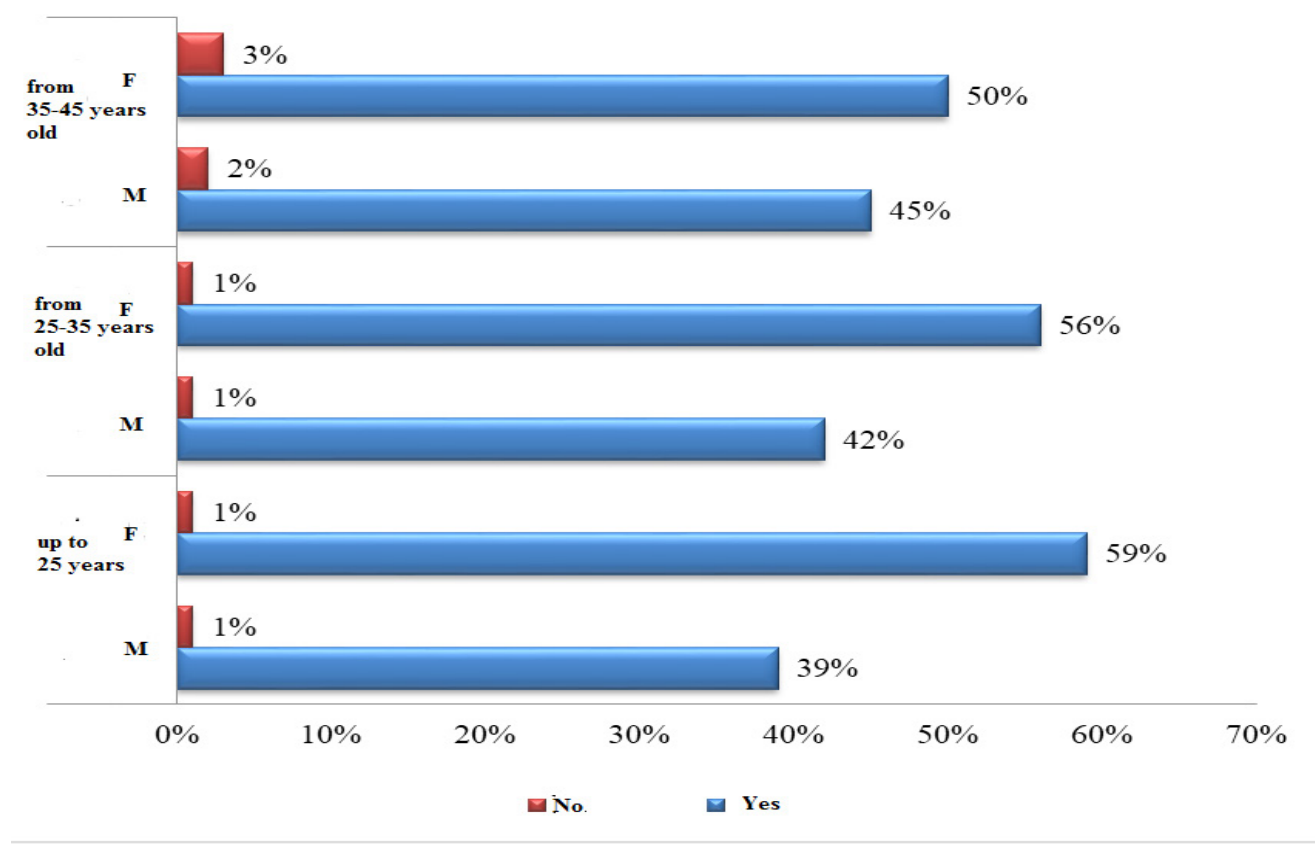

\section{Source:Author's calculation}

Based on Figure 3. we can conclude that absolutely all respondents, both male and female, allocate a large sum of money for food, which only confirms the fact and the reality that "Serbia has the lowest standard but on the other hand, it also has European prices." 
The average expenditures for personal household consumption in Serbia in 2018 were on average 54,323 dinars per month.

According to the results, as many as 40 students answered that they allocate from 10,001 to 15,000 dinars a month for food, 34 students said that they spend 5,001 to 10,000 dinars per month, 30 students up to 5,000 dinars, 17 students consume food to the amount of 15,001-20,000 dinars, while 16 students answered that they shell out 20,001 to 25,000 dinars per month for food. Also, there were 2 respondents who spend over 30,000 dinars per month for food.

According to these results, it can be concluded that the monthly average which students spend on food is between 10,000 and 15,000 dinars.

The modern pace of life affects our eating habits in a negative way. Various Serbian and international research carried out in previous years show that Serbian citizens have unbalanced diets, fail to consume enough fruits and vegetables, and often make mistakes when choosing and preparing food.

Thus, as a result of bad eating habits, there is a noticeable growth in the number of overweight and obese persons in Serbia. Experts say that the basic principle of proper nutrition can be summarized in three words: moderate - diverse - adequate.

Meals should be diverse. By consuming only fruits, vegetables and cereals, a sufficient amount of minerals and vitamins is sure to be ingested. Eating foods containing healthy fats, such as olive oil, fruits and blue fish, keeps us healthy.

Figure 4. Do you think you eat healthy?

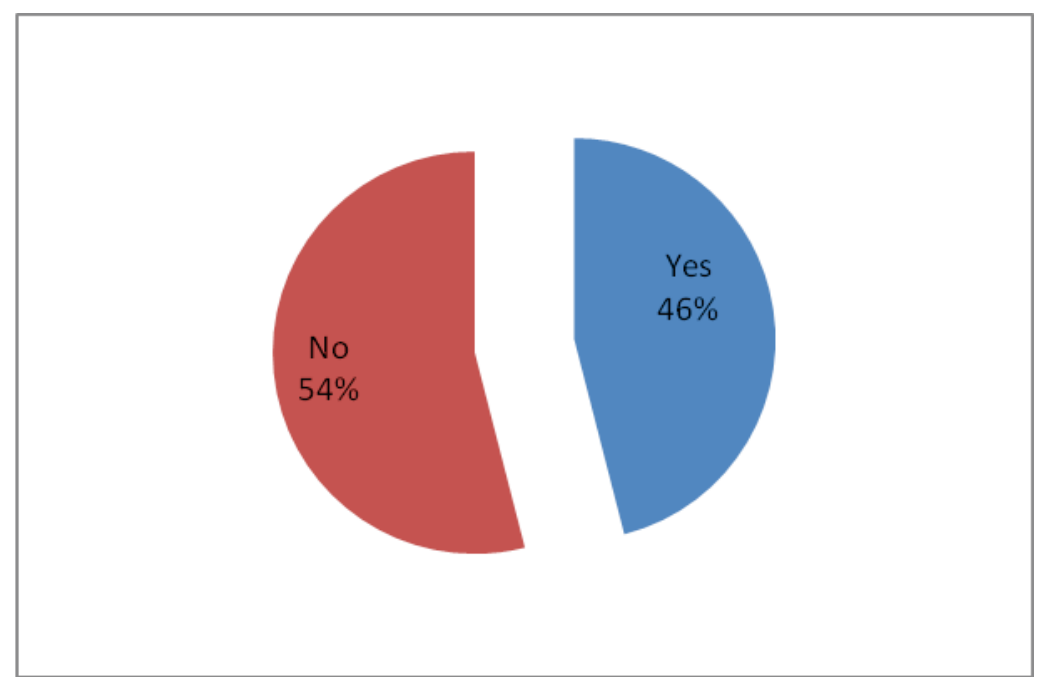

Source:Author's calculation

The results show that the largest number of students - 81 or $46 \%$ - consider that they do not eat healthy, while 69 or 54\% claim they have healthy eating habits. 
According to these results, it can be concluded that among the 150 students surveyed, the majority claimed they had unhealthy eating habits, which can be linked to several factors, such as poor eating habits, a fast pace of life associated with everyday stress, as well as the price of groceries which was identified as the limiting factor for purchasing groceries.

Organic food contains no additives allowed in inorganic foods such as hydrogenated fats, aspartame or artificial colors and flavors. It also has no pesticides or herbicides the causes of many diseases, as well as GM compounds. By its composition, organic food has significantly higher levels of vitamins and minerals.

Research has shown that organic food contains, for example, an average of $63 \%$ more potassium, $73 \%$ more iron and $125 \%$ calcium than products obtained by conventional agriculture, and the share of dry matter content in organic products is higher by up to $30 \%$. In order for some vegetables to be regarded as organic foods, they must be grown according to the following rules:

a) Pesticides cannot be used, or herbicides and similar agents. Organic food must be grown at least three years without chemicals.

b) The fields must have clear boundaries so that plants have no contact with chemicals from the neighboring fields.

c) Genetic engineering is prohibited - everything has to be in line with nature.

d) Pest problems are solved naturally - by setting traps and baits.

When it comes to organic foods of animal origin, the rules are as follows: there are no hormones that artificially promote growth, drugs or other artificial agents in animal nutrition.

Does organic food really have a beneficial effect on health? There is clear scientific evidence of the positive impact of organic food on human health. Research in Germany has shown that organic products have a significantly higher content of oligo minerals, especially potassium and iron, as well as a higher level of magnesium, phosphorus and vitamin C. Similar results have also been obtained in the USA, where it was established that these products account for $63 \%$ more potassium, $73 \%$ more iron and $125 \%$ more calcium than products from conventional agriculture. According to the World Health Organization (WHO), 1-5 million cases of pesticide poisoning are recorded annually, with 20,000 fatalities. It is products of animal origin of unverified quality, the most common sources of alimentary toxinfection, that usually end up on the market.

There were almost no vegetarians among the students. Namely, 148 students who participated in the survey responded that they were not vegetarians, and only 2 respondents confirmed that they were not meat eaters.

In most cases, the students eat in fast food restaurants as it is cheaper. When they have time, they consume hot meals in the canteen, and when they are busy with their daily activities, they usually buy fast food. In general, students eat in the way their daily commitments and finances allow them to. 
Figure 5. Rate on a scale of 1-10 how often you ingest the given foodstuffs.

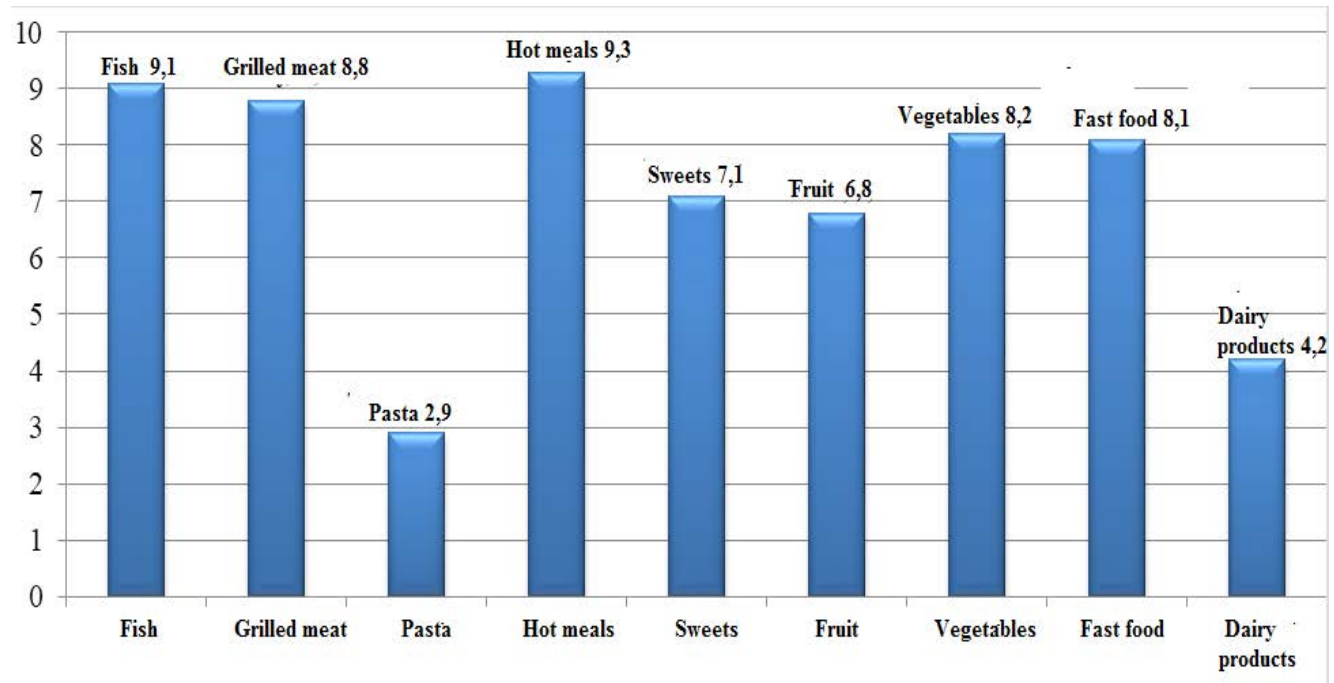

Source:Author's calculation

Students prefer to eat cooked meals, rating them by an average of 9.3. Following that, they like to eat fish - 9.1, grilled meat - 8.8, vegetables -8.2 , fast food -8.1 , sweets -7.1 , fruits -6.8 , dairy products -4.2 , while the least students prefer to eat pasta -2.9 . The general conclusion is that students mostly like hot meals that are prepared in their own homes.

A number of student drives took place in Smederevska Palanka in April of 2018. Within the framework of the "We choose proper nutrition in order to be healthier" drive which was held in front of the Institute for Student Health Protection of Smederevska Palanka, an exhibit of foods recommended for everyday nutrition was presented. Students from various departments prepared meals made up of fresh fruit and vegetables, and the Institute volunteers provided information on the importance and nutrition of certain foods, as well as their preparation.

Also, student volunteers polled their peers about their eating habits, as well as sharing promotional health education materials, determining the quantity of nutrition and pointing out the importance of preventive screening. This was also an opportunity to interview several participants (students).

The results obtained were as follows: 65 students claimed that they cook regularly, 53 students liked to cook occasionally, 32 students said they disliked cooking. This result can be connected with extra free time that enables this type of activity, or insufficient finances for restaurant meals.

Generally speaking, most students of all ages dislike cooking, although a number like it, and the female respondents were the majority in the overall structure of the surveyed students, as was expected. 
Figure 6. Do you cook (depending on the gender and age of the respondents)?

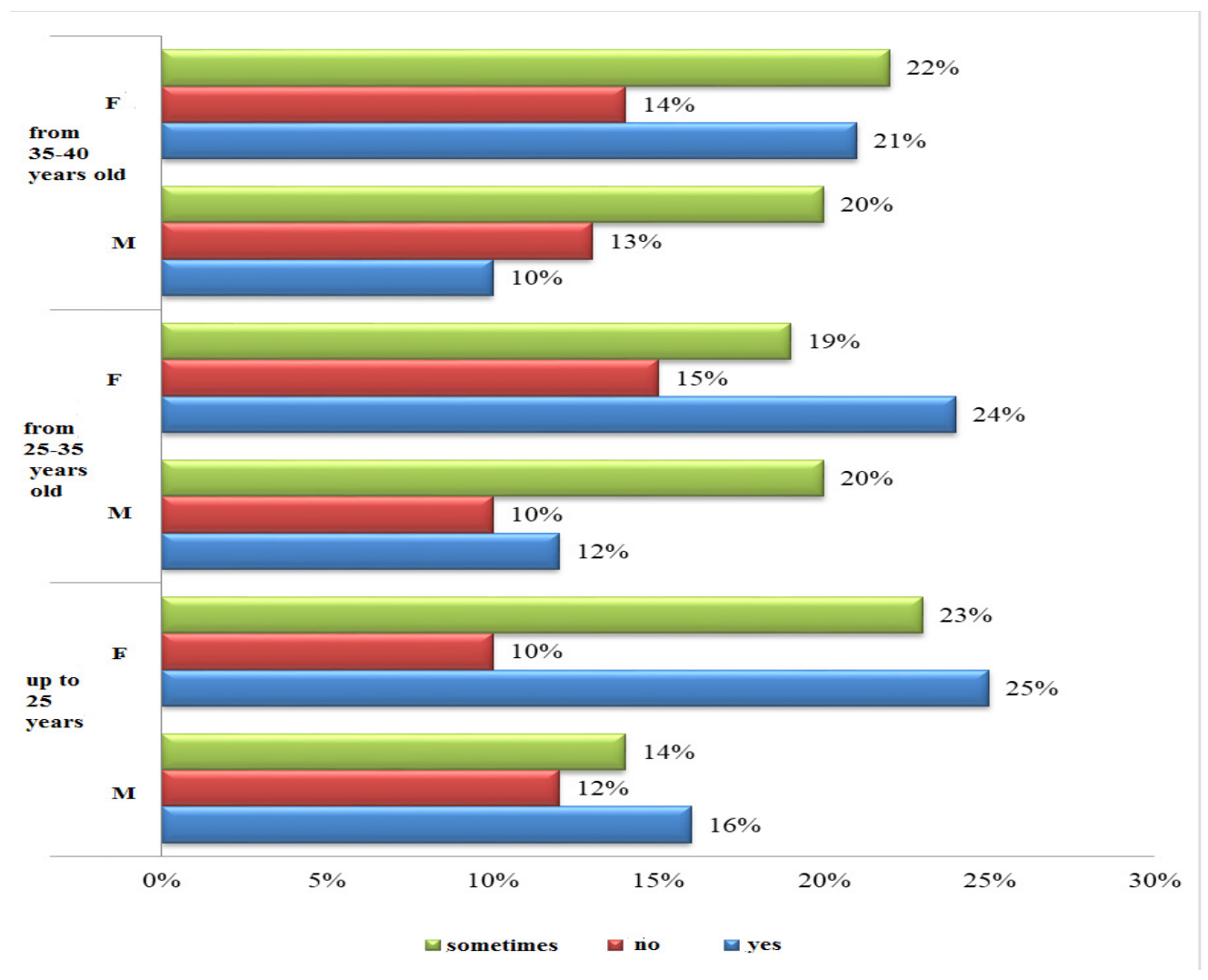

Source: Author's calculation

We can conclude that students have no habit of cooking. Whether this occurs due to ignorance, or in the belief that insufficient funds fail to provide quality ingredients for a good meal can be examined in a further analysis.

Based on numerous research by the Ministry of Youth and Sports of the Republic of Serbia, there is the conclusion that as many as $25 \%$ of students are not involved with sports, and many, even at an early age, suffer from problems with joints, stomach pains and frequent headaches.

Also, every fourth student is a so-called couch potato, which means they take little or no exercise and spend their free time lying down and eating.

In addition, most students have poor dietary habits and eat mostly ready-made or frozen meals - meaning that food need not be healthy as long as it's fast. The bad diets of the students are supported by the number of fast food restaurants that can be found around the university campuses (for example, there are 7 fast food restaurants around the Smederevska Palanka university site, which only confirms the previously stated). 
According to the survey, 71 respondents stated that they prefer to eat at home, 54 students enjoy eating in fast food restaurants, while 25 respondents like to eat in fine restaurants. According to these results, it can be concluded that the majority of students like to eat at home. This result can be linked to a previous conclusion whereupon most students like to cook, as well as the existence of the limiting factor for fine restaurant dining - in short, money.

When it comes to the reasons for students choosing food, they were ranked from 1 to 5 in the following results. When choosing food, most students answered that health reasons were the most important, ranking health with the highest average score of 4.7.

Figure 7. Rate reasons on a scale of 1-5: your choice of food type?

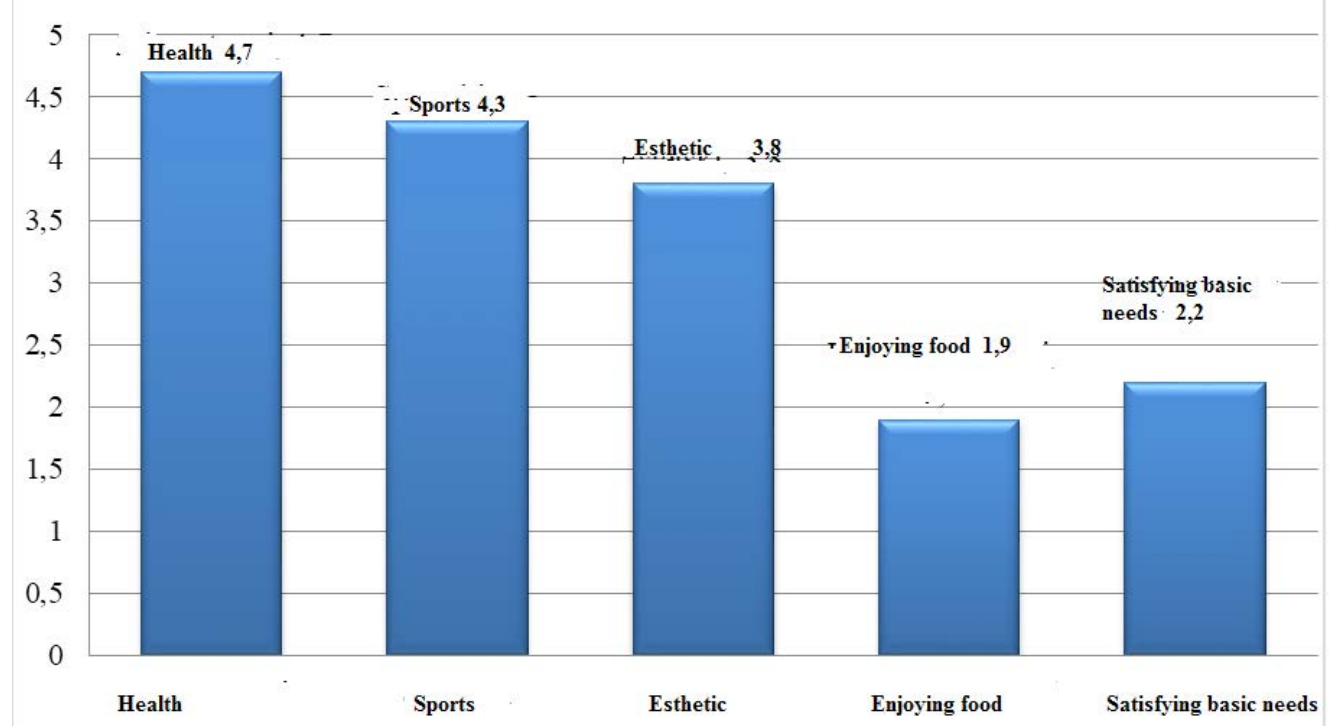

Source: Author's calculation

Following health reasons, students rated sports with the average mark of 4.3 , then esthetic reasons with an average mark of 3.8. The lowest average score was satisfying basic needs with a score of 2.2 and enjoying food with an average mark of 1.9. According to these results, it can be said that most students pay attention to food choices and that health reasons are the most important.

The largest number of students (58 respondents) filled in the additional field in the questionnaire, claiming their favorite food were hot meals. After this, 26 students preferred a burger, 23 students liked pizzas, while 12 students opted for fruit salad or dairy products as the additional option. 
Figure 8. If you could choose, which foods would you opt for?

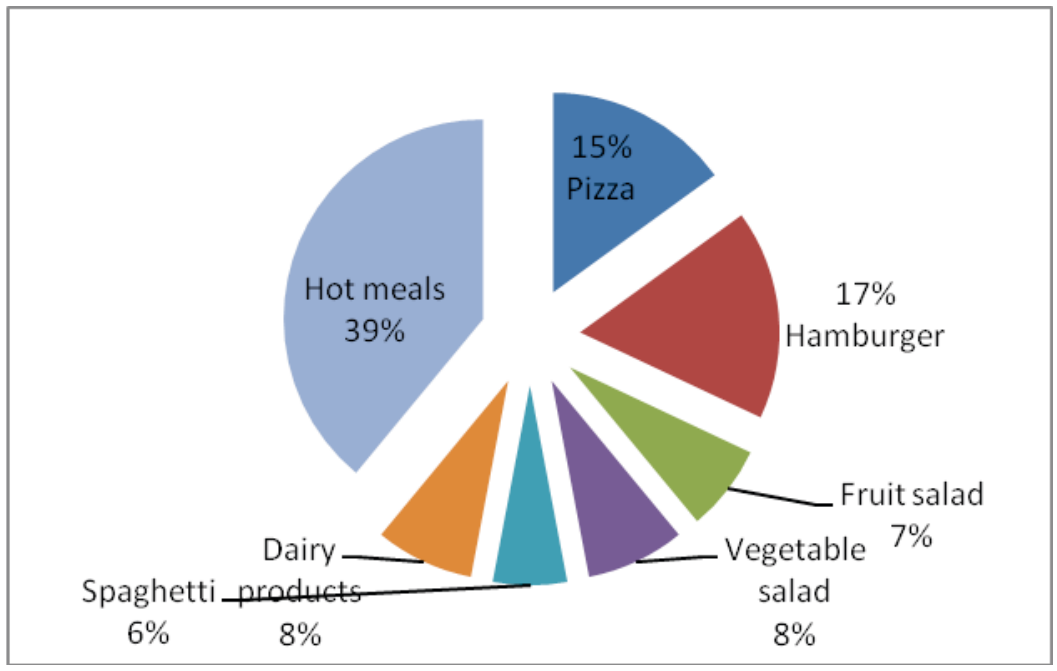

Source: Authors calculation

According to these results, at least 9 students selected spaghetti as the additional option in the questionnaire. According to these results, it can be seen that the largest number of students like hot meals, which can be linked with previous questions regarding their preference for domestic meals.

The question arising is this: what is healthy today, especially when we are inundated with information about contaminated and genetically modified foods? Healthy eating "requires a lot of money," many people claim. They also state that sports also take time and money, and since that is untrue, the claim is rejected.

Figure 9. Do you think that there is a healthy diet nowadays?

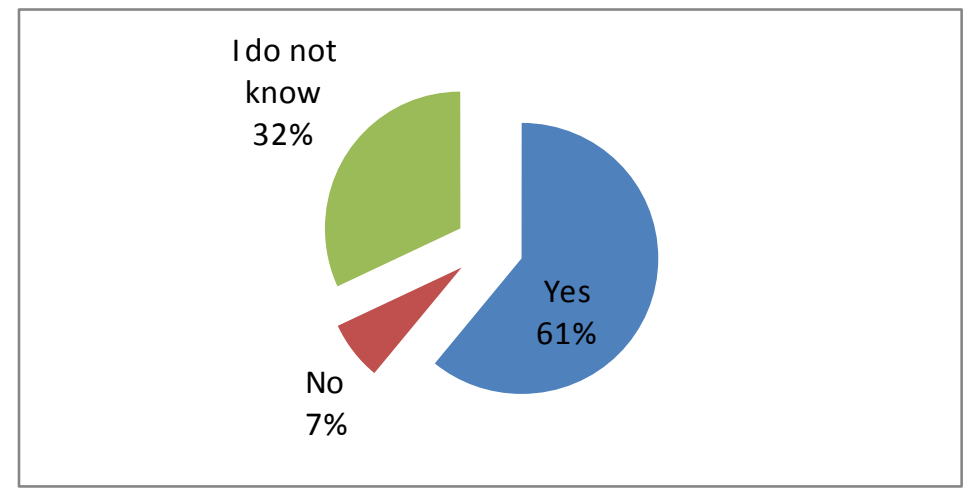

Source: Authors calculation

According to the results, 91 students think that healthy food exists today, 48 students answered with 'I do not know,' while 11 students answered that such as thing as healthy food does not exist. 
Based on this, we can conclude that a large number of respondents lacks the necessary information on the basis of which they could conclude whether there is healthy food today. This could be amended by introducing certain subjects through school curricula primarily in primary and secondary education, so that all students can have the necessary information.

It is very difficult to know what we are actually buying at supermarkets or grocery stores - whether the cabbage was picked beside the highway and full of heavy metal exhaust gases or not is hard to weigh up. We don't even have the information how a farmer applies agrotechnical measures: where the vegetable was grown, how much it was sprayed and with what. We have no idea if the nice old woman selling apples really picked them in her garden or bought them from a wholesaler.

Vegetables and fruits from plantations are grown under controlled conditions, which means that pesticides, insecticides and other products are used as much as it is necessary, and no more than that. Going to the green market can be quite interesting, but you are seriously mistaken if you think that you can find healthy food there.

When shopping, the majority of students pay no attention to the origin and production method of the food products - 51 students. On the other hand, 39 students sometimes pay attention when buying food, while 35 students always check the origin of the food while purchasing. When it comes to GMO, 15 students have no idea what it is, while 10 students claim that they have no idea what organic food is.

According to these results, I can conclude that the majority of students pay no attention to the origin of food when purchasing it, while a substantial number are not familiar with the terms and meaning of GMO.

When asked where they buy organic products, 1 student responded in the supermarket, 6 students said on a farm, 8 students on a green market, and 9 students heeded advice from friends. However, the largest number, 126 respondents, bought no organic products at all.

Figure 10. Where do you buy organic products?

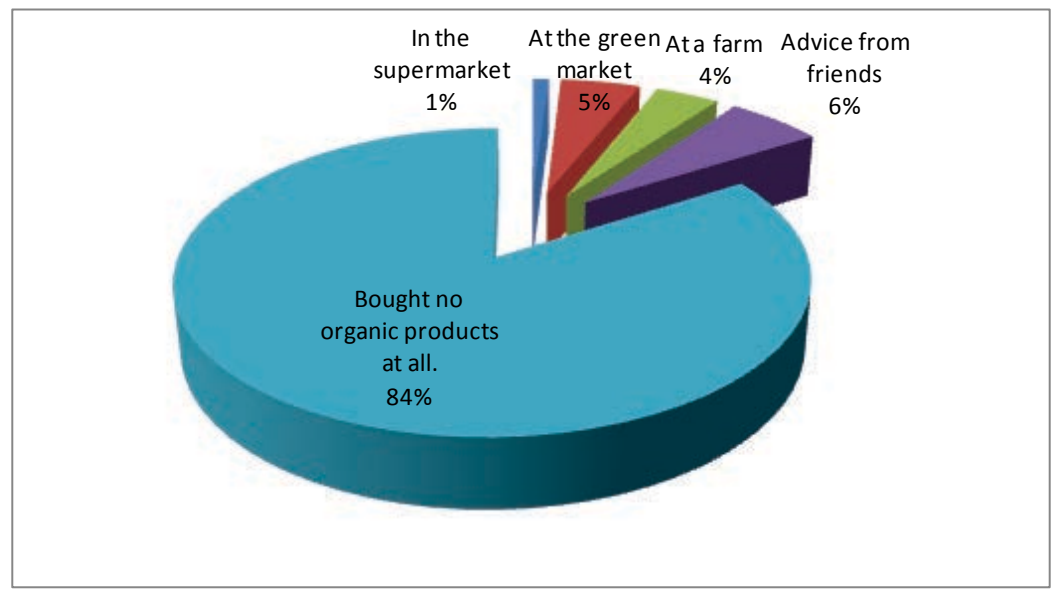

Source: Authors calculation 
In addition to the fact that a large section of the students surveyed still lack knowledge of the true meaning of GMO as well as organic foods and all their disadvantages and advantages, this is a somewhat expected result.

\section{Discussions}

The student population was submitted to a barrage of questions about their eating habits, from the why and how and with whom students eat, as well as the ways in which students buy, prepare and consume food.

On the basis of a comparative comparison of the results of this research and the international research papers mentioned in the analysis, there is an obvious disagreement in the results and dietary habits of the student population. So far, a number of global and domestic researches have been carried out to compare both organic and inorganic foods. On the one hand, we have those who claim that organic food is healthier because it is nutritionally more useful. On the other hand, some suggest that this food is actually less healthy because it can contain a higher amount of mycotoxins due to pesticides not being used.

In a global sense, as far as nutrition and mycotoxins are concerned, there is no significant difference between organic and conventional foods. Although the level of pesticide residues in conventional foods is controlled and must not exceed a certain limit, organic food undoubtedly has fewer pesticide residues. Based on the research, we come to the conclusion that the price of food is a very important factor, in accordance with the living standard of the population of Serbia; in our case - students. The bulk of students pay no attention to the origin of foods when purchasing groceries, while a substantial number are unfamiliar with the terms and meaning of GMO. Considering the fact that a large number of the students remain in the dark about the meaning of GMO and organic food and all the disadvantages and advantages thereof, this is a somewhat expected result, given the weak response of the manufacturers of this type of food in Serbia, as well as their placement, marketing, and national and local institutions that provide insufficient marketing and market space for these foods.

\section{Conclusions}

In our opinion, despite the fact that the younger generations pay little attention to the origin of food, one of the problems and obstacles that could be improved in the coming period is greater media coverage of organic products, which is still lacking due to the aggressive advertising of various other products. If more attention was paid to presenting information of the harmful effects of GMO as well as the benefits of organic food, it is without doubt that a larger number of students would check the origin of the product, as well as where to find and buy organic products.

In addition, it needs to be said that a more aggressive campaign offering general information as well as information about the possibilities of growing organic food and informing others of all its benefits can be organized only with the aid of the state, ministries, local self-governments, etc. 


\section{Conflict of interests}

The authors declare no conflict of interest.

\section{References}

1. Djokic, N., Grubor, A., Milicevic, N., \& Petrov, V. (2018). New market segmentation knowledge in the function of bioeconomy development in Serbia. Amfiteatru Economic, 20(49), 700-716.

2. Golijan J, Popović A. (2016): Basic characteristics of the organic agriculture market. Proceedings of the Fifth International Conference Competitiveness Acta Agriculturae Serbica, Vol. XXIII, 46(2018); 125-140 137 Of Agro-Food And Environmental Economy, 10-11 November 2016, Bucharest: 236-244.

3. Gracia, A., \& de-Magistris, T. (2016). Consumer preferences for food labeling: what ranks first?. Food Control, 61, 39-46.

4. Grubor, A., Đokić, N., \& Milićević, N. (2018). Serbian organic food consumer profile: Contradictions of previous researches and methodological possibilities. Škola biznisa, (1), 123-130.

5. Heinze, K., (2016): European organic market grew to more than 26 billion euros in 2014, Organic-Market Info, available at: http://organic-market.info/news-inbriefand-reports-article/european-organic-market-grew-to-more-than-26-billioneurosin-2014.html.

6. Kranjac, M., Vapa-Tankosic, J., \& Knežević, M. (2017). Profile of organic food consumers. Economics of agriculture, 64(2), 497-514.

7. Lazić B. (2010): Organska poljoprivreda - zalog za budućnost. Organic news, 1: 8-9. [in English: Lazić B. (2010): Organic agriculture - a pledge for the future. Organic news, 1: 8-9.].

8. Ministarstvo poljoprivrede i zaštite životne sredine, 2016. http://www.dnrl.minpolj. gov.rs. [in English: Ministry of Agriculture and Environmental Protection. 2016. http://www.dnrl.minpolj. gov.rs.].

9. Ristić L., Bošković N, Knežević M. (2018), Resource potential and perspective of the development of organic agriculture in the Republic of Serbia, Institutional changes as a determinant of economic development of the Republic of Serbia, Faculty of Economics, Kragujevac

10. Sahota, A. (2015). The global market for organic food \& drink. In H. Willer \& J. Lernoud (Eds.), The World of organic agriculture. Statistics and emerging trends 2015 (pp. 120-123). Bonn: Research Institute of Organic Agriculture (FiBL), Frick, and IFOAM - Organics International.

11. Vlahović, B., Radojević, V., \& Živanić, I. (2011). Istraživanje stavova potrošača o potrošnji organske hrane u Srbiji. Ekonomika poljoprivrede, 58(3), 443-456. [in English: Vlahović, B., Radojević, V. i Živanić, I. (2011) Survey of Consumer Attitudes on Organic Food Consumption in Serbia, Economics of Agriculture, 58(3), 443-456.]. 
12. Zakić, N., Bugarčić, M., \& Milovanović, M. (2017). Proclivity for open innovation in the case of agricultural and food companies in Serbia. International Review, (34), 64-71.

13. Zanoli, R., \& Naspetti, S. (2002). Consumer motivations in the purchase of organic food: a means-end approach. British food journal, 104(8), 643-653. 